Research paper

\title{
Prevalence of Enterobius vermicularis infection among schoolchildren attending four selected schools in the Hambantota district of Sri Lanka GSA Gunawardena ${ }^{1}$, MH Gunatilleke $^{1}$, MM Ismail $^{2}$
}

Sri Lankan Journal of Infectious Diseases 2013 Vol.3(2):17-20

DOI: http://dx.doi.org/10.4038/sljid.v3i2.5467

Key words: pinworm infection; enterobiasis; diagnosis; scotch-tape; Sri Lanka

\begin{abstract}
Enterobiasis is one of the commonest human parasitic infections in the world. Diagnosis of enterobiasis is by demonstration of eggs or adult worms by sampling the perianal and perineal skin using adhesive cellulose tape (scotch tape). This study determined the prevalence of Enterobius vermicularis (pinworm) infection among 483 schoolchildren attending four selected schools in the Hambantota district. The prevalence of infection was $6.2 \%(n=30)$. Since pinworm infection is a family infection, the implications are that at least 30 families are infected. Further studies are needed to understand the prevalence, distribution and the physical and psychological impact of pinworm infection in the population.
\end{abstract}

\section{Introduction}

Enterobius vermicularis or the pinworm, a small nematode, is the causative agent of enterobiasis, which is considered to be one of the commonest human parasitic infections in the world. ${ }^{1}$ Children are more commonly affected than adults. The main clinical features experienced are pruritus ani, vulvitis and general symptoms such as insomnia and restlessness. A considerable proportion of children show loss of appetite and weight, irritability, emotional instability and enuresis. ${ }^{2}$ Occasionally, the adult stage migrates to unusual sites and produce granulomatous lesions. ${ }^{3}$

Infection in humans is initiated by the ingestion of infective eggs which hatch in the caecal region of the large intestine and develop into adult worms within 4-6 weeks. After fertilization, the gravid female worm migrates down the colon during the night and deposits a large number of sticky eggs on the perianal and perineal skin of the host, which become infective within a few hours.

Although a history of perianal itching, irritability, and insomnia may suggest a pinworm infection, diagnosis depends on demonstrating the eggs or adult worms. This is normally achieved by sampling the perianal and perineal skin by using adhesive cellulose tape (scotch

${ }^{1}$ Department of Parasitology, Faculty of Medicine, University of Colombo, Sri Lanka

${ }^{2}$ 159, Kynsey Road, Colombo 08, Sri Lanka

Address for correspondence: Dr GSA. Gunawardena, Department of Parasitology, Faculty of Medicine, University of Colombo, P. O. Box 271, Kynsey Road, Colombo 8, Sri Lanka

E-mail: sharminigunawardena@hotmail.com; Tel.no: +94(0)112695300 
tape), which is applied, sticky side down, to the skin. The tape is then transferred to a glass slide and examined under the microscope for the presence of eggs. ${ }^{1}$ Pinworm eggs are usually not found in faeces unless the infection is heavy.

A Health and Nutrition programme, approved by the Ministries of Health and Education, was conducted in December 2005 in fifteen randomly selected schools of the Hambantota district. As a part of this programme, a stool survey was done to determine the prevalence of soil-transmitted nematode infections among 1344 schoolchildren attending these schools, using the Kato-Katz technique (unpublished data). The results of this survey revealed a virtual absence of soiltransmitted nematode infections ( 1 hookworm; 2 whipworm; 0 roundworm infections). However, $21(1.6 \%)$ schoolchildren were positive for pinworm ova in their stools, indicating a high intensity of pinworm infection among these schoolchildren. Therefore, this study was done to determine the prevalence of pinworm infection among schoolchildren attending four selected schools (different schools from the previous survey) in the Hambantota district of Sri Lanka.

\section{Materials and Methods}

\section{Study area and population}

The study was conducted in January 2006, after obtaining permission from the relevant authorities of the four selected schools in the Hambantota district. Mothers were summoned to the school and the purpose of the study was explained in detail to them. After obtaining verbal consent, they were each given a scotch tape kit. They were requested to swab the perianal area of their child with the sticky side of the scotch tape that would be revealed by pulling back the small tab kept on the tape. The procedure was clearly demonstrated to them with the use of a mannequin. They were asked to use the swab before the child went to the toilet in the morning to prevent any pinworms eggs being washed from the area.

\section{Parasitological techniques}

Five hundred and ninety two (592) swabs were distributed and 498 were submitted for examination. Of the 498 kits returned, 15 did not have identification tags and were excluded from analysis. The swabs were placed in polythene bags with identification tags carrying the name, age, sex and class of the child. The swabs were brought to the Department of Parasitology, Faculty of Medicine, University of Colombo, for examination.

Parasitological examination was done by placing the scotch tape on a glass slide and examining under a microscope. A drop or two of glycerine was placed under the scotch tape to aid visualization of the ova. Those positive for pinworm eggs were recorded. Infected schoolchildren as well as their families were treated with mebendazole $100 \mathrm{mg}$ given twice daily for three days which was repeated two weeks later.

\section{Results}

A total of 483 schoolchildren aged between 4 and 12 years (mean=9.0) participated in the study (Table 1). In this sample, 237 children $(49.1 \%)$ were males. Thirty $(6.2 \%)$ schoolchildren were positive for pinworm infection. Almost $67 \%$ of infections were found among children aged 9 10 years $(n=20)$. The prevalence of infection between sexes were comparable with 17 females 
$(6.9 \%)$ and 13 males $(5.5 \%)$ being infected $\left(\chi^{2}=0.42 ; P=0.52\right)$. The number of infected schoolchildren varied from $3(4.1 \%)$ to $11(7.5 \%)$ between the four schools surveyed $\left(\chi^{2}=1.23\right.$; $P=0.75)$.

Table 1 : The number of samples examined and the number of positives in each school.

\begin{tabular}{|c|c|c|}
\hline School & Number examined & Number positive (\%) \\
\hline 1 & 73 & $03(4.1)$ \\
\hline 2 & 166 & $09(5.4)$ \\
\hline 3 & 97 & $07(7.2)$ \\
\hline 4 & 147 & $11(7.5)$ \\
\hline TOTAL & 483 & $30(6.2)$ \\
\hline
\end{tabular}

\section{Discussion}

Enterobius vermicularis infection, although considered to be highly prevalent throughout temperate and tropical regions, has received comparatively little attention so far as studies on intestinal parasites are concerned. This is probably because infection is seldom observed to be acutely symptomatic, or perhaps, because the available diagnostic techniques are cumbersome and not practically suited to do large scale studies. Apart from reports on incidental findings of pinworm eggs in stools being examined for other intestinal parasitic infections, no previous studies have been conducted to evaluate the prevalence of enterobiasis in Sri Lanka. Thus the result of this survey gives an insight into the distribution of pinworm infection among some schoolchildren within the Hambantota district.

Many studies worldwide have revealed higher prevalence rates of infection than in our study. In Korea, several studies revealed prevalence rates of between $9.2 \%$ and $18.5 \%$. In Nigeria, the prevalence of infection was found to be $7.5 \%^{6}$, while in Thailand it was $38.8 \%$ and in Venezuela it was $19.1 \%^{8}$. However, very low prevalence rates of $0.62 \%$ and $0.0 \%$ were found in pre-school children in Taiwan ${ }^{9}$ and in an urban area in Thailand. ${ }^{10}$

Enterobiasis is commonly associated with overcrowding and poor personal hygiene. According to the national demographic and health survey data of 2006-7, ${ }^{11}$ the average size of the household was 4.0 in the rural sector (which includes the Hambantota district). In addition, a single dose of mebendazole $(500 \mathrm{mg})$ is offered routinely to schoolchildren of grades 1,4 and 7 through annual school medical inspections while teaching of good health habits is carried out in all the schools. In this background, a low prevalence of infection in our study population is not surprising. Unfortunately, no other reported data on prevalence of enterobiasis is available for comparison within the country and rates of infection may very well vary according to location.

Pinworm infection is considered as a group or family infection with all members of the household or institution being infected, especially under crowded conditions. Therefore, even though only 30 schoolchildren were found to be positive in this survey, the implications are that at least 30 families are infected. The whole family is thus treated to prevent re-infection. In pinworm infections, chemotherapy must be combined with education and personal hygiene aimed at preventing autoinfection. Although it is possible to effect a temporary cure, eradication 
may prove difficult because of re-infection from the contaminated environment or from asymptomatic members of the same household. Eradication may necessitate several repeated courses of treatment up to a year or more. Further studies are necessary to understand the prevalence, distribution and the physical and psychological impact of pinworm infection in the population.

\section{Acknowledgements}

We sincerely thank Dr. Mark Bradley for his valuable advice and suggestions in carrying out this study. We also thank the International Relief and Development, Sri Lanka for financial assistance.

\section{References}

1. Garcia LS and Bruckner DA (eds). Diagnostic Medical Parasitology ( $2^{\text {nd }}$ ed). Washington DC: American Society for Microbiology, 1993: pp184 - 212.

2. Manson-Bahr PEC and Apted FIC (eds). Manson's Tropical Diseases $\left(18^{\text {th }} \mathrm{ed}\right)$. London: Baillere Tindall, 1983: p199.

3. Chandrasoma PT and Mendis KN. Enterobius vermicularis in ectopic sites. Am J Trop Med Hyg 1977; 26:644-9. No doi

4. Yoon HJ, Choi YJ, Lee SU, Park HY, Huh S, Yang YS. Enterobius vermicularis egg positive rate of pre-school children in Chunchon, Korea. Korean J Parasitol 2000; 38: 279-81. http://dx.doi.org/10.3347/kjp.2000.38.4.279

5. Park J, Han E, Kim W, Shin E, Guk S, Kim J and Chai J. A survey of Enterobius vermicularis infection among children on western and southern coastal islands of the Republic of Korea. Korean J Parasitol 2005; 43:129-34. http://dx.doi.org/10.3347/kjp.2005.43.4.129

6. Otu-Bassey IB, Ejezie GC, Epoke J and Useh MF. Enterobiasis and its relationship with anal itching and enuresis among school-age children in Calabar, Nigeria. Ann Trop Med Parasit 2005; 99:611-6. http://dx.doi.org/10.1179/136485905X51481

7. Nithikathkul C, Changsap B, Wannapinyosheep S, Poister C and Boontan P. The prevalence of Enterobius vermicularis among primary school students in Samut Prakan Province, Thailand. Southeast Asian J Trop Med Public Health 2001; 32(Suppl 2):133-7. No doi

8. Devera R, Perez C and Ramos Y. Enterobiasis in students from Ciudad Bolivar, Venezuela. Boletin Chileno de Parasitologia 1998;5 3:14-8. No doi

9. Chang TK, Liao C.W, Huang YC, Chang CC, Chou CM, Tsay HC, Huang A, Guu SF, Kao TC and Fan CK. Prevalence of Enterobius vermicularis infection among preschool children in kindergartens of Taipei City, Taiwan in 2008. Korean J Parasitol 2009; 47: 185-7. http://dx.doi.org/10.3347/kjp.2009.47.2.185

10. Pethleart A, Saichua P, Rhongbutsri P, Leelawongtawon R, Aree K, Tiengtip R, Nithikathkul C, Nateeworanart S, Taylor WR. Prevalence and risk factors for pinworm infection in the kindergarten of Thammasat University, Thailand. Southeast Asian J Trop Med Public Health 2010; 41(2):306-10. No doi

11. Department of Census and Statistics, Sri Lanka. http://www.statistics.gov.lk Last accessed on $6^{\text {th }}$ August 2013. 